\title{
La contabilidad en tiempos de pandemia
}

\author{
Accounting in times of pandemic
}

Norma del Rocío Toledo Castillo. ${ }^{1}$, Isabel Romané Peñafiel Moncayo. ${ }^{2}$ \& Maritza Guadalupe Puente Vásquez. ${ }^{3}$

DOI: https://doi.org/10.33262/visionariodigital.v5i1.1527

\begin{abstract}
Summary
Introduction. In this article, we want to make an analysis of the importance that the accounts would carry out in these times in which there has been a global productive slowdown, in some way we want to collect the economic impact that is being experienced worldwide and what factors accountants become vulnerable in the decisions that have to be made to get out of this crisis, which unfortunately is not only health but also economic and social. Conclusions. COVID-19 not only brought a health crisis but also a political and social crisis, as we can see poverty increases, giving an unusual case, that it is not the poor who go out to steal and assault, but it is this corrupt system that has caused a political elite assaults the resources of the poorest. The pandemic is causing changes in the history of mankind. This event will mark a before and after in human civilization. It is evident that the gap between rich and poor after this pandemic will be much greater, especially in our countries, that is why more social alternatives that benefit humanity and the environment must be rethought.
\end{abstract}

Keywords: accounting, crisis, pandemic, globalization and economic.

\section{Resumen}

Introducción. En este artículo, se quiere hacer un análisis de la importancia que sería llevar las cuentas en estos tiempos en donde se ha dado una desaceleración productiva

1 Escuela Superior Politécnica de Chimborazo, Riobamba Ecuador norma.toledo@espoch.edu.ec https://orcid.org/0000-0003-1116-760X

2 Escuela Superior Politécnica de Chimborazo, Riobamba Ecuador romane.peñafiel@espoch.edu.ec https://orcid.org/0000-0002-2629-8576

3 Escuela Superior Politécnica de Chimborazo, Riobamba Ecuador Maritza.puente@espoch.edu.ec https://orcid.org/0000-0002-0376-5821 
global, de alguna manera se quiere recopilar el impacto económico que se está viviendo a nivel mundial y que factores contables se vuelven vulnerables en las decisiones que se tenga que tomar para salir de esta crisis que lamentablemente no solo es sanitaria sino económica y social. Conclusiones. El COVID-19 no solo trajo una crisis sanitaria sino política y social, como podemos observar la pobreza se incrementa, dándose un caso insólito, que no son los pobres los que salen a robar y asaltar, sino es este sistema corrupto se ha provocado que una elite politiquera asalte los recursos de los más pobres. La pandemia está provocando cambios en la historia de la humanidad. Este acontecimiento marcará antes y un después en la civilización humana. Es evidente que la brecha entre ricos y pobres después de esta pandemia será mucho mayor, especialmente en nuestros países, es por eso que hay que replantearse alternativas más sociales que vayan en beneficio de la humanidad y del medio ambiente.

Palabras claves: contabilidad, crisis, pandemia, globalización y económico.

\section{Introducción.}

"Parado en el museo, traté de imaginar cómo, en una inimaginablemente remota tarde, un anónimo ancestro registró una transacción de animales dibujando signos y al hacer eso inventó el mágico arte de la escritura. La escritura -me di cuenta- fue inventada no por un poeta, sino por un contador”. (Manguel, 2002).

Con esta frase nos podemos dar cuenta que la contabilidad ha estado presente desde épocas remotas, por lo tanto no se puede decir, que es creación del capitalismo financiero global, ni ha aparecido a partir de la sistematización de la partida doble por parte del conocido Fray Luca Paccioli, a fines del siglo XV, ni tras la crisis financiera de 1929, aun reconociendo la fuerte impronta que dicho acontecimiento tuvo sobre la regulación y la construcción y difusión de estados financieros.. Esta ciencia para unos y disciplina para otros, ofrecer información fiable acerca de la realidad económica y financiera tanto de un pequeño negocio como de grandes grupos empresariales, con la finalidad de facilitar la toma de decisiones financieras, estratégicas y de control, tan necesarias en el día a día de una empresa.

Los usuarios de dicha información no se limitan únicamente a los dueños o propietarios, sino a un grupo heterogéneo de usuarios interesados en conocer dicha información. Así mismo, a lo largo de la historia, la humanidad ha estado sometida a diferentes escenarios que han puesto en peligro la supervivencia sobre la tierra y entre éstos, han estado las pestes o pandemias que ha destruido a civilizaciones enteras, pero el ser humano siempre las ha superado, siempre ha iniciado de nuevo, en esa larga historia evolutiva de tratar de ser el

"El Señor de la Tierra". Y a lo largo de este proceso constantemente ha tenido que adaptarse a las nuevas condiciones y para ello constantemente realizado un ajuste de cuentas entre lo que tiene y lo que debe gastar, porque de ello dependía, depende y dependerá su estancia 
sobre este planeta. Es así, que en este mundo globalizado hasta las pandemias adquirieron esta proporción, el brote del COVID-19 se propagado rápidamente por todo el mundo, Latinoamérica y en particular nuestro país no fue la excepción.

El virus ha llegado hasta a las comunidades más lejanas, en estos cuatro meses desde que se conoció el primer caso, con un número significativo de personas infectadas.

Las medidas adoptadas por los gobiernos para detener el virus, ha sido el confinamiento, especialmente durante los primeros meses de pandemia, produciéndose prácticamente un cese de toda actividad comercial, afectando a la actividad económica, y por ende implicaciones en el sistema financiero y de seguro va a producirse implicaciones contables severas para muchas entidades, provocando: interrupciones en la producción, inestabilidad laboral, falta de suministro, reducción de la productividad, cierre de empresas, negocios, etc., retroceso en la expansión de negocios, dificultad para mejorar las finanzas, mayor volatilidad en el valor de los instrumentos financieros, reducción del turismo, interrupciones de viajes no esenciales y deportes, actividades culturales y de ocio.

\section{La importancia de la contabilidad}

Se dice que toda empresa o entidad tiene que incluir un sistema contable para llevar el control sobre el conjunto de actividades económicas y financieras, es decir, todo lo que tenga una dimensión económica en una empresa tiene una repercusión contable. La contabilidad es el medio de proporcionar información financiera fiable, esta rama nos ayuda a desarrollar normas contables que ayudan o apoyan al desarrollo económico.

La contabilidad establece el estado contable o financiero, que resume la situación económicofinanciera de una empresa para permitir la toma de decisiones de accionistas, inversores, acreedores, propietarios y otros. Este concepto involucra tanto a las denominadas pequeñas y medianas empresas (conocidas con el acrónimo de PYMES) como a las grandes multinacionales; esto obedece tanto a razones de índole financiera, de términos de asegurar la adecuada rentabilidad, como en términos fiscales, debido a la presión de los fiscos federales, provinciales y locales sobre cada estructura empresarial.

Con este pequeño análisis de la importancia de la contabilidad, podemos darnos cuenta que hoy más que nunca la contabilidad juega un papel importante en estos tiempos de pandemia, como se dijo en líneas más arriba, ella nos dará la bases para poder reorganizar nuestra economía y poder salir adelante en estos momentos que nos hallamos de vacas flacas.

\section{Impacto Económico}

Constantemente estamos viendo en los diferentes medios de comunicación, el impacto económico que esta pandemia ha provocado en el planeta, dándose un impacto directo en la producción, fácilmente se puede ver como los países que manejan la economía mundial han 
desacelerado su producción, como es el caso de la misma China que ha tenido efectos sobre los exportadores de ese país, que según el Banco Mundial, las mayores fuentes de importaciones de China son Corea, el Japón y otros países asiáticos.

Otro punto que se ha vuelto vulnerable es la cadena de suministros, por el mismo hecho de los inconvenientes de las exportaciones de los chinos, esta ha hecho que muchas industrias manufacturas no puedan acceder a los insumos importados de la China, cayendo nuevamente en una deceleración productiva, y las empresas que más sufrirán serán las medianas y pequeñas, ya que obviamente, la magnitud del impacto dependerá de la velocidad con la que se desaparezca el virus, porque las medidas tomadas para controlar el virus, lamentablemente ha sido el confinamiento. Igualmente se observa el grave problema financiero que se viene a nivel mundial, este estancamiento en las actividades productivas igualmente está provocando un debilitamiento en los mercados financieros, la falta de circulante provocará posiblemente alargar los plazos de los préstamos bancarios, provocando pérdidas, así mismo, al aumentar el riesgo estas empresas adopten medidas de inversión que no sean rentables.

Podría suceder una disminución significativa de los mercados de valores y de bonos corporativos, debido a que los inversores casi siempre prefieren mantener los valores gubernamentales (en particular los del tesoro de los Estados Unidos) sobre todo en esta incertidumbre creada por la pandemia.

El año del virus. Aunque la propagación de la enfermedad en China se ralentiza, los brotes se producen de forma continua en todo el mundo. Cada brote requiere una desaceleración de la producción en esa zona, y en un mundo globalizado, eso significa que se producen interrupciones continuas en diferentes regiones e industrias a medida que se producen y controlan los brotes. El efecto general es perturbar la actividad económica lo suficiente como para desacelerar considerablemente el crecimiento mundial.

Las empresas que sean lo suficientemente ágiles para gestionar el cambio de proveedores y que tengan suficiente liquidez para sobrevivir a períodos de bajas ventas e ingresos tendrán una ventaja competitiva. En definitiva, la gente ha entrado en pánico por la propagación del virus, porque junto a él se está propagando otros virus como el de la corrupción, provocando que se ahondan aún más los impactos sanitario, económico y social. Esta crisis ha provocado un despido masivo de trabajadores. Según el modelo de previsión a muy corto plazo de la OIT, se estima que, a nivel mundial, el número de horas de trabajo disminuyó de alrededor del 4,5 por ciento (lo cual equivale a 130 millones de empleos a tiempo completo en el primer trimestre de 2020, suponiendo un trabajo de 48 horas semanales), en comparación a la situación anterior a la crisis (cuarto trimestre de 2019).

Igualmente, la OIT, indica que conjuntamente, los empleadores y los trabajadores por cuenta propia, alrededor de 436 millones de empresas de los sectores más afectados en todo el mundo enfrentan un alto riesgo de experimentar graves perturbaciones. Más de la mitad de 
estas empresas -unos 232 millones- están en el comercio al por menor y al por mayor, uno de los sectores más afectados actualmente a nivel mundial. Los trabajadores independientes representan el 45 por ciento del empleo en este segmento.

En cuanto a la economía informal este mismo organismo indicó que casi 1600 millones de trabajadores de esta rama se verán afectados por las mediadas de confinamiento o por trabajar en sectores muy afectados. Según KPMG tendencias, realiza un análisis de las áreas de los estados financieros con mayor probabilidad de resultar afectadas por la situación actual:

\section{Hipótesis de negocio en marcha}

Si bien la elasticidad entre oferta y demanda sugiere que los mercados tienden al equilibrio como principio macroeconómico, necesariamente existirá afectación del flujo económico de la renta. Si esto no ocurre pronto no existirá capital de trabajo o continuidad de la planta de personal, y se empezarán a prescindir de aquellos cargos no necesarios, dando paso a la reingeniería de cargos.

Pagos efectuados durante la contingencia: verificar que exista claridad de los pagos entre el inicio y el fin, que tengan relación de causalidad y estén aprobados por gerencia. Esto necesariamente derivará de solicitud de soportes adicionales de los movimientos transaccionales del sistema.

Deterioro del valor de los activos: especialmente de los no financieros. La evaluación de estados financieros de períodos intermedios requerirá que se valide si la maquinaria está afectada por el riesgo país y la inflación que ya estamos viviendo con el alza en la tasa representativa del mercado.

Pasivos por obligaciones, gravámenes y tasas: estar atento al pago de impuestos, a la creación de nuevos impuestos o reformas tributarias que hagan sostenible el pago de créditos otorgados por bancos de segundo piso y la regla fiscal.

Inversiones en asociadas y negocios conjuntos: si bien el porcentaje de participación no cambia por efecto de la pandemia, el avance de las operaciones, especialmente en el sector de la construcción, se verá afectado.

Inventarios y activos movibles: sin duda, el cálculo del valor neto de realización por modelo, obsolescencia, precios más bajos, la divisa y operaciones que no tienen coberturas en importación y exportación pueden hacer variar este rubro.

Instrumentos financieros y arrendamientos: el riesgo crediticio al no existir ingresos puede derivar en impagos, especialmente si se realizaron inversiones en bienes de capital Capex, por sus siglas en inglés. La NIIF 9 y la NIC 39 plantean entre los escenarios un posible cambio de modelo de negocio, a causa de los picos del COVID-19 y su curva de crecimiento exponencial. 
Actualización de matrices: de control interno, de las fuerzas de Porter, del COSO y de las pérdidas máximas esperadas y soportables.

Valor razonable de instrumentos financieros: al estar expuestos al precio que un tercero aceptaría y es capaz de pagar por el bien, surgirían variaciones en este valor, especialmente por la incertidumbre, el cambio de hábitos y la pérdida de confianza de los consumidores.

Subvenciones o apoyos económicos del estado: rebajas de impuestos y moratorias.

Provisiones: si bien la NIC 37 - Provisiones, pasivos y activos contingentes indica que no es posible hacer provisiones sobre pérdidas futuras, algunas decisiones como clausuras o finiquitos de contratos pueden ocasionar el uso de provisiones. Por ello es menester que los administradores conozcan las novedades que pueden incurrir en su actividad, para poder actuar de manera oportuna en los impactos de las distintas áreas contables. Las empresas en general se ven afectadas por falta de liquidez y pérdidas viéndose afectada su solvencia financiera y mercantil, y esto no pasa solo con las empresas sino con las familias que debido a este confinamiento ha sido cada día más difícil tener esta solvencia.

La importancia de la contabilidad.-Es hora de enfocarnos en la importancia que tiene esta ciencia o disciplina y las contribuciones que puede ofrecer para enfrentar los desafíos que se generaran en esta época como resultado de este estancamiento económico global, ayudando a mejorar la toma de decisiones no solo a la empresas como tal sino talvez desde el punto de vista personal, para que la contabilidad sea vista con un enfoque más social, y pueda dar esa contribución a esta sociedad con información de mejor calidad no solo desde el punto de vista financiero y económico sino social de organizaciones porque solo juntos podremos salir adelante.

Hay que hacer una aclaración, que la crisis económica ya estaba planteada antes de la pandemia, ésta, solo vino a agravarla, el calentamiento global y los problemas sociales en el mundo, paulatinamente han ido provocando esta crisis, la falta de ética de los grandes monopolios, la manera irracional de obtener las materias primas, sobre todo en nuestros países tercer mundistas, han provocado que la brecha entre ricos y pobres sea cada día mayor, y ahora con la pandemia como se ha dicho, lo único que hizo fue agravar la situación. Por lo tanto, en estos momentos es importante contar con información de calidad no solo de carácter financiero y económico sino de tipo social y ambiental. Kolaja y Koller (2020) señalan que los CFO de las grandes empresas, para dar respuesta a las preocupaciones de los inversores, deberían plantearse las siguientes preguntas: ¿Qué exactamente le está haciendo el COVID19 a sus negocios? 
Esto ayudará a diagnosticar la demanda y la oferta para enfrentar cómo será el desempeño y como podría responderá a cada circunstancia dada ¿Qué acciones específicas se están tomando para proteger los negocios? Aquí se recomienda seguir las recomendaciones dada por la OMS y en nuestro caso del GOE Nacional. ¿Tienen los negocios suficiente liquidez para sobrevivir? Esto conlleva determinar la liquidez, como se la va a mantener durante esta recesión, determinando cuales podrían ser sus ganancias, buscando fuente de acreditación y algunas otras decisiones importantes que ayuden a solventar esta estabilidad. ¿Se pueden proporcionar estimaciones? Se necesita realizar planes de asignación de capital, especialmente con las políticas de dividendos, gastos de capital y fusiones y adquisiciones.

De esta manera estamos obteniendo información precisa para poder tomar las mejores decisiones en momentos de crisis, y así darle, un vuelco a nuestras actividades económicas o a su vez dar el mejor criterio a quien lo necesite. Por lo tanto, se vuelve a recalcar que en época de COVID-19, la utilización de información predictiva es de vital importancia en los ejercicios que se cierren en época de pandemia como la desvalorización de activos financieros y no financieros, las perdidas por incobrabilidad, y la recuperación de activos por impuestos diferidos entre otras.

Esto hace que el papel del contador juegue un papel importante ya sea como asesor, auditor o prestando sus servicios a diferentes tipos de organizaciones, teniendo obviamente en cuenta las disposiciones que día a día van surgiendo para apalear en algo esta crisis financiera, sobre todo de la PYMES y los monotributarios.

El contador por lo tanto deberá estar atento a afinar sus habilidades para brindar su conocimiento en dar una luz de esperanza a esta sociedad basada totalmente en un mundo globalizado y comercial.

\section{Conclusiones.}

- El COVID-19 no solo trajo una crisis sanitaria sino política y social, como podemos observar la pobreza se incrementa, dándose un caso insólito, que no son los pobres los que salen a robar y asaltar, sino es este sistema corrupto se ha provocado que una elite politiquera asalte los recursos de los más pobres.

- La pandemia está provocando cambios en la historia de la humanidad. Este acontecimiento marcará antes y un después en la civilización humana, se nota claramente que provocará cambios drásticos en la humanidad, como toda pandemia ha producido a lo largo de la humanidad.

- Es evidente que la brecha entre ricos y pobres después de esta pandemia será mucho mayor, especialmente en nuestros países, es por eso que hay que replantearse alternativas más sociales que vayan en beneficio no solo de la humanidad sino del medio ambiente, porque no debemos olvidar que la crisis ya estaba planteada antes 
de la pandemia, las extracciones de los recursos no renovables ya provocaron una desestabilización ambiental social y económica y que la pandemia solo vino a agravarla.

- Nuestra supervivencia en la tierra dependerá sino como seres humanos somos capaces de vivir en comunión, porque la tierra siempre proveerá de lo que necesite el hombre, pero solo cuando tenga la capacidad de coger solo lo que necesite, sin que se de ese gran desperdicio que hoy por hoy vemos toneladas de "basura" que solo es el producto de la sobreproducción mundial. Es ahora en estos momentos donde el contador puede apoyar con sus conocimientos, para apoyar en ese ahorro de recursos con el fin de disminuir el colapso de esas PYMES

\section{Referencias Bibliográficas.}

Corporativos, T. S. (Junio de 2020). ¿Como Afecta En La Contabilidad El Covid-19? Obtenido de https://www.tfc.com.ec/uploads/noticia/adjunto/670/Boletin__Como_Afecta_En_La_Contabilidad_El_Covid_19.pdf

Debell, T., \& Kalidas, V. (marzo de 2020). A fondo: Implicaciones contables de los efectos. Obtenido de https://www.pwc.com/ia/es/publicaciones/noticias-niif/Afondo-implicaciones-contables-de-los-efectos-del-coronavirus.pdf

González, A. (02 de mayo de 2020). Observatorio de la OIT: El COVID-19 y el mundo del trabajo. Obtenido de http://www.rrhhdigital.com/secciones/mercadolaboral/141577/index.php?id_seccion=45

Jumbo, D., Campuzano, J., Vega, F., \& Luna, Á. (2020). Crisis económicas y Covid-19 en Ecuador: impacto en las exportaciones. Universidad y Sociedad, 103-110. Obtenido de https://rus.ucf.edu.cu/index.php/rus/article/view/1883

KPMG. (Agosto de 2020). Una revisión del impacto económico del COVID-19 en América del Sur. Obtenido de https://assets.kpmg/content/dam/kpmg/co/sac/pdf/2020/08/una-revision-delimpacto-de-covid-19-en-america-del-sur.pdf

Martínez, I. R., Martínez, L. C., \& Vázquez, I. I. (s.f.). La importancia del análisis de los estados financieros en la toma de decisiones. Universidad Autónoma del Estado de Hidalgo. Obtenido de https://www.uaeh.edu.mx/scige/boletin/tlahuelilpan/n4/e2.html

Morales, A. M., Pineda, C. M., \& Monsalve, O. O. (2017). Aportes de Fray Luca Pacioli al desarrollo de la contabilidad: Origen y difusion de la partida doble. ESPACIOS, 38(34). doi:ISSN 07981015 
Mundo, B. N. (02 de marzo de 2020). Coronavirus: el mapa que muestra el número de infectados y muertos en el mundo por covid-19. Obtenido de https://www.bbc.com/mundo/noticias-51705060

Nardacchione, D. (2020). Contabilidad en tiempos de pandemia. EDICON. Obtenido de http://edicon.org.ar/producto/contabilidad-en-tiempos-de-pandemia/

OIT. (23 de Septiembre de 2020). Observatorio de la OIT:a COVID-19 y el mundo del trabajo. Obtenido de https://www.ilo.org/wcmsp5/groups/public/---dgreports/--dcomm/documents/briefingnote/wcms_755917.pdf

Ramírez, M. d. (2003). Contabilidad y responsabilidad social:un camino por recorrer. Instituto de Investigaciones Contables “Profesor Juan Alberto Arévalo”(18). Obtenido de http://bibliotecadigital.econ.uba.ar/download/cya/cya_v9_n18_05.pdf

Ramirez, M. d. (2020). La Contabilidad En Tiempos Del Covid-19. Universidad de Buenos Aires, Facultad de Ciencias Económicas, Centro de Investigaciones en Auditoria y Responsabilidad Social (CIARS).(51). doi:ISSN 1852-446X

Wyman, H. (09 de marzo de 1990). El poder y la importancia de la contabilidad. Revista Española de Financiación y Contabilidad. Obtenido de http://www.observatorioiberoamericano.org/ricg/n\%C2\%BA_19/Rogerio_Joao_Lunkes;_Vicente_Ripoll_y_ Fabricia_Silva_da_Rosa.pdf

\section{【Lignital}




\section{PARA CITAR EL ARTÍCULO INDEXADO.}

Toledo Castillo, N. del R., Peñafiel Moncayo, I. R., \& Puente Vásquez, M. G. (2021). La contabilidad en tiempos de pandemia. Visionario Digital, 5(1), 26-35. https://doi.org/10.33262/visionariodigital.v5i1.1527

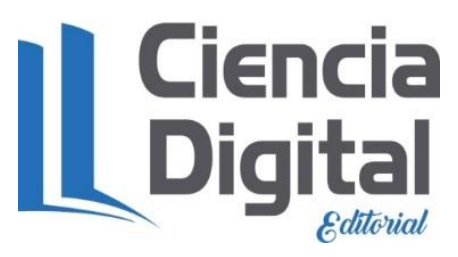

El artículo que se publica es de exclusiva responsabilidad de los autores y no necesariamente reflejan el pensamiento de la Revista Visionario Digital.

El artículo queda en propiedad de la revista y, por tanto, su publicación parcial y/o total en otro medio tiene que ser autorizado por el director de la Revista Visionario Digital.
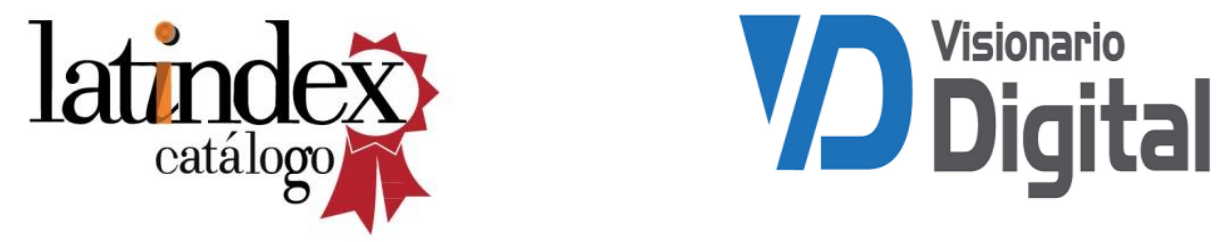